\title{
Lichen Planus Sparing the Extremity Affected by Poliomyelitis: The Profound Role of Neuroinflammation in Disease Development
}

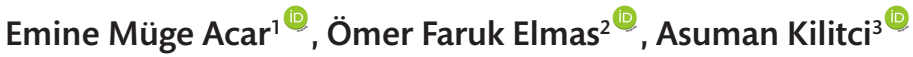 \\ ${ }^{1}$ Ahi Evran University Education and Research Hospital, Dermatology, Kırşehir, Turkey \\ ${ }^{2}$ Ahi Evran University, Medical Faculty, Dermatology, Kırşehir, Turkey \\ ${ }^{3}$ Ahi Evran University, Medical Faculty, Pathology, Kırşehir, Turkey \\ Address for Correspondence: Asuman Kilitci, E-mail: drasuk@gmail.com \\ Received: 07.07.2019; Accepted: 16.09.2019; Available Online Date: 27.01 .2020 \\ (C) opyright 2019 by Dokuz Eylül University, Institute of Health Sciences - Available online at www.jbachs.org
}

Cite this article as: Acar EM, Elmas ÖF, Kilitci A. Lichen Planus Sparing the Extremity Affected by Poliomyelitis: The Profound Role of Neuroinflammation in Disease Development. J Basic Clin Health Sci 2020; 1:88-89.

Lichen planus is a chronic inflammatory disease affecting the skin and mucous membranes. The etiology is not exactly known but genetic, immunological, and environmental factors have been implicated (1). Psychosomatic factors have also been associated with disease onset and progression; in addition, there is increasing data in the literature supporting a neurophysiological pathogenesis of the disease $(2,3)$.

A 42-year-old female patient presented to our department with an erythematous pruritic eruption for the last year. The patient denied any allergen exposure or drug use at the onset of the lesions. On physical examination, purple polygonal papules were observed on both wrists and the dorsum of right foot. The lesions were mildly pruritic. The absence of lesions on the left lower limb that had become paretic after poliomyelitis was striking (Figure 1). This extremity showed muscle weakness but no sensory deficit on neurological examination. The skin biopsy revealed hyperkeratosis, acanthosis, parakeratosis, band-like lymphoid infiltrate, and colloid bodies. A diagnosis of lichen planus was established (Figure 2 ).

The neurological system is in close relationship with the immune system by means of the sympathetic nerve traffic, hormones, neuropeptides, and cytokines (4). Changes in peripheral innervation and nociception in oral lichen planus as well as the therapeutic response to benzodiazepines suggest a possible role of neuroinflammation in disease etiopathogenesis $(1,3)$.

Poliomyelitis is a selective motor neuropathy that is the result of the destruction of lower motor neurons of the central nervous system due to a poliovirus infection. Cutaneous sensory nerves are known not to be affected in poliomyelitis. However, Prokhorenko et al. detected sensory disturbances in aging patients with remote poliomyelitis but concluded that the relationship between poliomyelitis and sensory disturbances was unclear and more studies are required to confirm this relationship (5).

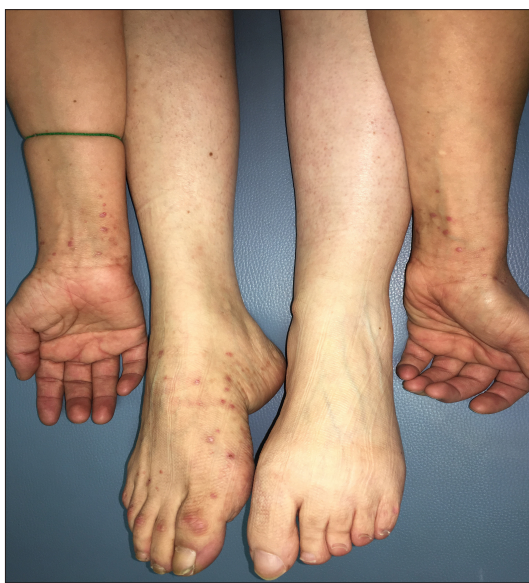

Figure 1. Purple polygonal papules on bilateral wrists and on the dorsum of right foot. Note sparing of the left foot.

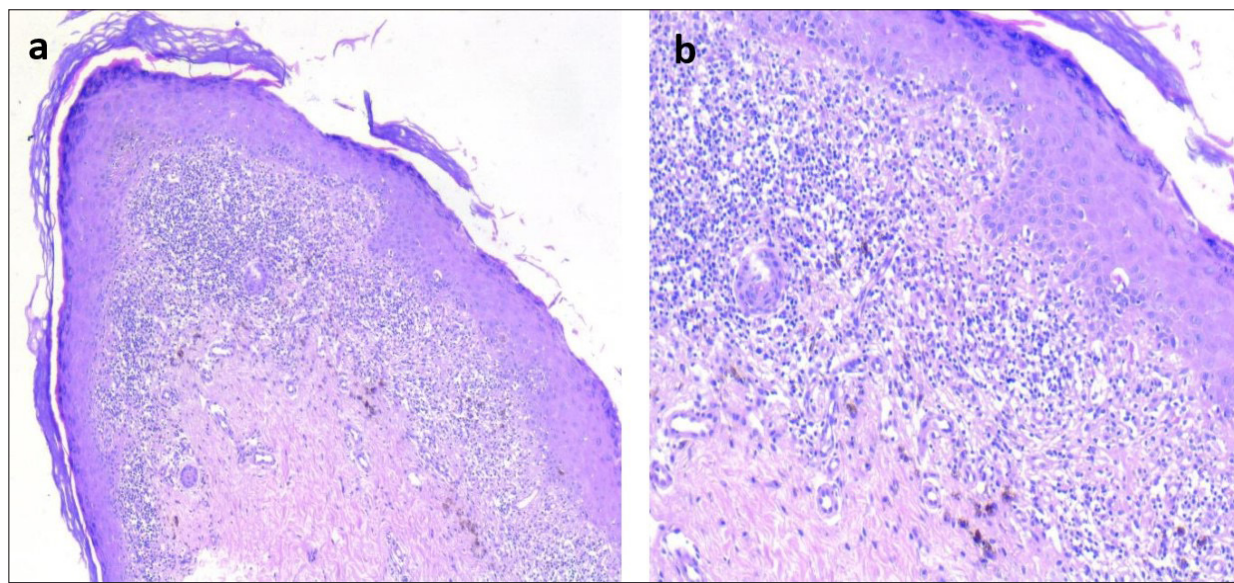

Figure 2 (a,b). (HE X50, HE X100): On histopathological examination, subepidermal band-like lymphoid infiltrate, hyperkeratosis, acanthosis, hypergranulosis, melanophages and colloid bodies. 
"The immune compromised cutaneous district " theory implies a cutaneous site which has been damaged by burns, vaccinations, radiation and traumas including neurologic injury. Immune alterations in these areas can be defective or excessive, depending on the neuropeptides involved. The exact mechanisms leading to these different responses to the same injury has not been fully elucidated (6). In literature, papillomatosis cutis lymphostatica arising on a polio paraplegic area, unilateral bullous pemphigoid on a hemiplegic side after cerebral stroke, and unilateral rosacea on facial palsy have been reported as examples of some skin diseases developing in neurologically affected areas (6). On the contrary, " sparing phenomenon " on the neurologically denervated skin has also been reported in psoriasis and scleroderma, both of which have a bilateral and symmetrical distribution $(7,8)$. If we consider lichen planus as another skin disease with a similar distribution, we believe that this feature is noteworthy, possibly as a result of an impairment in the neurophysiological pathways affecting cutaneous immunological responses in the paretic or paralytic extremity, while lesion development is observed in the contralateral side. A deficiency in the production of neurotrophic factors due to the atrophy and changes in blood flow is another factor that might have contributed to the sparing phenomenon (4).

Our case supports the profound significance of an intact neural system in the development of lichen planus. Understanding the neuroinflammatory mechanisms in lichen planus will shed light on the disease etiopathogenesis and contribute to developing new treatment options.

\section{REFERENCES}

1. Guarneri F, Guarneri C, Marini H. Oral lichen planus and neurogenic inflammation: new observations and therapeutic implications from four clinical cases. Dermatol Ther 2014;27:206-210. [CrossRef]

2. Sandhu SV, Sandhu, JS, Bansal H, Dua V. Oral lichen planus and stress: An appraisal. Contemp Clinical Dent 2014;5:352-356. [CrossRef]

3. Chattipakorn S, Ittichaicharoen J, Rangdaeng S, Chattipakorn N. Changes in peripheral innervation and nociception in reticular type and erosive type of oral lichen planus. Indian J Dent Res 2011;22:678683. [CrossRef]

4. Tarkowski E, Naver H, Wallin BG, Blomstrand C, Grimby G, Tarkowski A. Lateralization of cutaneous inflammatory responses in patients with unilateral paresis after poliomyelitis. J Neuroimmunol 1996;67:1-6. [CrossRef]

5. Prokhorenko OA, Vasconcelos OM, Lupu VD, Campbell WW, Jabbari B. Sensory physiology assessed by evoked potentials in survivors of poliomyelitis. Muscle Nerve 2008;38:1266-1271. [CrossRef]

6. Piccolo V, Russo, T, Ruocco E, Baroni A. Selective localization or sparing of skin disorders in neurologically injured areas: an underestimated connubium. Indian J Dermatol 2014;59:612. [CrossRef]

7. Zhu TH, Nakamura M, Farahnik B, et al. The Role of the Nervous System in the Pathophysiology of Psoriasis: A Review of Cases of Psoriasis Remission or Improvement Following Denervation Injury. Am J Clin Dermatol 2016;17:257-263. [CrossRef]

8. Sethi S, Sequeira W. Sparing effect of hemiplegia on scleroderma. Ann Rheum Dis 1990;49:999-1000. [CrossRef] 